\title{
Indenizações que envolvem o parto à luz do entendimento do Superior Tribunal de Justiça - STJ
}

\author{
Indemnities involving childbirth birth of the Superior Tribunal de Justiça-STJ's \\ understanding
}

Indemnizaciones que implican el parto a la luz del entendimiento del Superior Tribunal de Justiça-STJ

\author{
Thaísa Mara Leal Cintra Rodrigues ${ }^{1}$ \\ Altacilio Aparecido Nunes ${ }^{2}$
}

RESUMO: Introdução - O Ministério da Saúde tem apostado na mudança da cultura do parto, a fim de estabelecer diretrizes baseadas na assistência humanizada. Os médicos obstetras têm papel relevante nesse processo, pois participam de maneira ativa na aplicação do conhecimento e das melhores técnicas para realização de um parto seguro. Métodos - O trabalho analisou o discurso dos julgadores do Superior Tribunal de Justiça (STJ), nas ações indenizatórias envolvendo partos, mediante o estudo do Discurso do Sujeito Coletivo (DSC), o qual reflete opiniões e posicionamentos relacionados à área médica obstétrica. Resultados - O discurso dos julgadores do STJ ressaltou a responsabilidade objetiva dos hospitais, sejam públicos ou privados, ao passo que aos médicos foi atribuída a responsabilidade subjetiva, devendo ser comprovada a culpa do profissional. As provas periciais produzidas foram essenciais para o desfecho da ação. As ações improcedentes sustentaram que a obrigação de meio excluiu a responsabilidade, desde que realizados todos os procedimentos necessários e adequados. A União foi considerada parte ilegítima para responder pelos danos relacionados ao Sistema Único de Saúde. Discussão - Os discursos sugerem discussões acerca da mudança gradativa entre os envolvidos no processo gestacional e puerperal, inclusive aos operadores do direito, aplicadores da lei ao caso concreto, assim como aos profissionais da saúde obstétrica no exercício da profissão. Conclusão - Os casos analisados debateram sobre os riscos da prática médica obstétrica, o que pode ser objeto de reflexão, a fim de reduzir custos provenientes das altas indenizações, bem como incentivar a humanização, a qualidade e excelência na assistência ao parto.

Palavras-chave: Decisões Judiciais. Obstetrícia. Parto Normal. Cesária.

ABSTRACT: Introduction - The Ministry of Health has focused on changing the birth culture in order to establish guidelines based on humanized care. Obstetric physicians play an important role in this process, as they actively participate in the application of knowledge and the best techniques to perform a safe delivery. Methods - This study analyzed the discourse of the Supreme Court of Justice (STJ) judges, in the indemnity actions involving

\footnotetext{
${ }^{1}$ Mestre em Ciências pela Universidade de São Paulo - FMRP - Faculdade de Medicina de Ribeirão Preto. Especialista em Direito e Processo do Trabalho e Gestão Jurídica de Empresa pela UNESP - Universidade Paulista Julio Mesquita. Email: thaisalealcintra@gmail.com

${ }^{2}$ Faculdade de Medicina de Ribeirão Preto - Universidade de São Paulo. E-mail: altacilio@fmrp.usp.br
} 
deliveries, through the study of the Collective Subject Discourse (DSC), which reflects opinions and positions related to the obstetric medical area. Results - The STJ judges' speech emphasized the objective responsibility of hospitals, whether public or private, while physicians were assigned a subjective responsibility, and the professional's fault must be proven. The expert evidence produced was essential for the outcome of the action. The unfounded actions maintained that the obligation of means excluded liability, provided that all necessary and adequate procedures were carried out. Discussion - The speeches suggest discussions about the gradual change between those involved in the gestational and puerperal process, including the legal operators, law enforcers in the concrete case, as well as the And to obstetric health professionals in the practice of the profession. Conclusion - The cases analyzed discussed the risks of obstetric medical practice, which can be the object of reflection, in order to reduce costs from high indemnities, as well as to encourage humanization, quality and excellence in childbirth care.

Keywords: Judicial Decisions. Obstetrics. Natural Childbirth. Cesarean Section

RESUMEN: Introducción - El Ministerio de Salud ha apostado por el cambio de la cultura del parto, a fin de establecer directrices basadas en la asistencia humanizada. Los médicos obstetras tienen un papel relevante en este proceso, pues participan de manera activa en la aplicación del conocimiento y de las mejores técnicas para la realización de un parto seguro. Métodos - El trabajo analizó el discurso de los juzgadores del Superior Tribunal de Justicia (STJ), en las acciones indemnizadoras involucrando partos, mediante el estudio del Discurso del Sujeto Colectivo (DSC), el cual refleja opiniones y posicionamientos relacionados al área médica obstétrica. Resultados - El discurso de los jueces del STJ resaltó la responsabilidad objetiva de los hospitales, ya sean públicos o privados, mientras que a los médicos se les atribuyó la responsabilidad subjetiva, debiendo comprobarse la culpa del profesional. Las pruebas periciales producidas fueron esenciales para el desenlace de la acción. Las acciones improcedentes sostuvieron que la obligación de medio excluyó la responsabilidad, siempre que se efectuaran todos los procedimientos necesarios y adecuados. Discusión - Los discursos sugieren discusiones acerca del cambio gradual entre los involucrados en el proceso gestacional y puerperal, incluso a los operadores del derecho, aplicadores de la ley al caso concreto, así como a los profesionales de la salud obstétrica en el ejercicio de la profesión. Conclusión - Los casos analizados debatieron sobre los riesgos de la práctica médica obstétrica, lo que puede ser objeto de reflexión, a fin de reducir costos provenientes de las altas indemnizaciones, así como incentivar la humanización, la calidad y excelencia en la asistencia al parto.

Palabras-Ilave: Decisiones Judiciales.Obstetricia. Cesaria

\section{Introdução}

O Brasil possui uma das maiores taxas de cesarianas do mundo. Segundo os dados do Datasus, a última pesquisa revelou que em 2013 foram realizados 621.216 partos naturais e 792.490 cesarianas (1). As recomendações da Organização Mundial da Saúde são para que apenas de $10 \%$ a $15 \%$ dos partos sejam realizados por meio deste procedimento cirúrgico (2). Alguns fatores contribuíram para este resultado, tais como a 
evolução das técnicas cirúrgicas e anestésicas, os riscos reduzidos de complicações pósoperatórias imediatas, a prática obstétrica defensiva, as características do sistema de saúde e consequente remuneração, além da própria demanda das pacientes (3).

Em que pese o resultado demonstrar um notável progresso na assistência obstétrica, uma vez que várias razões médicas são aceitáveis, tendo em vista o melhor prognóstico materno e perinatal, existem argumentos contra a realização excessiva da cesariana. Alguns dados apontam que, aproximadamente, 850.000 cesarianas desnecessárias são realizadas a cada ano na América Latina (4). Estudos afirmam que a cesárea deveria ser evitada, uma vez que aumenta os riscos reprodutivos, sem prejuízo do desenvolvimento local, da capacitação do sistema de saúde, do tipo de paciente assistida e do nível de complexidade hospitalar. O procedimento é associado a alguns eventos adversos, tais como, maior necessidade de antibióticos após o parto; maior morbidade e mortalidade materna; aproximadamente, quatro a cinco vezes maiores que o parto natural; prematuridade; permanência em unidade de terapia intensiva (UTI) e morte neonatal. Por isso, a decisão tomada para realização de uma cesariana deve ser criteriosa e discutida com a paciente (2) (3) (5) (6).

Dessa forma, muito tem se discutido acerca do parto humanizado como um conjunto de propostas de mudança nas práticas obstétricas, a fim de levar aos serviços relacionados ao parto, conceitos novos e desafiadores e às vezes conflitantes, pois buscase maior humanização na assistência à parturiente e à criança que está sendo gerada. As abordagens baseadas em evidências científicas e as baseadas em direitos estão sendo recriadas e utilizadas como instrumentos para a mudança de cultura do parto (7).

Existem várias práticas realizadas pelos médicos obstetras necessárias desde o prénatal até o primeiro período do trabalho de parto. Não há evidências contra ou a favor do parto domiciliar ou em hospitais, porém estudos sugerem uma menor frequência de intervenções médicas no parto domiciliar. Destaca-se que no hospital, o parto na sala de PPP (pré-parto, parto e pós-parto) do centro obstétrico, associa-se também a menores intervenções médicas e maior satisfação materna (7) (8).

Uma revisão da literatura foi realizada na busca das melhores evidências disponíveis sobre a assistência ao primeiro período do trabalho de parto de forma mais humanizada. Foi abordado desde o local da assistência, a importância da definição do risco da gestante, até a posição da paciente e algumas intervenções, tais como, jejum, realização de enema, 
punção venosa e infusão de líquidos, tricotomia, deambulação, utilização do partograma, monitorização da frequência cardíaca fetal, manejo ativo do trabalho de parto com utilização de ocitocina e amniotomia precoce, o alívio da dor por métodos não farmacológicos, a analgesia de parto peridural e combinada, além do suporte contínuo intraparto (8). Neste estudo, constatou-se que procedimentos como jejum, tricotomia e enteróclise devem ser evitados, uma vez que não há evidências para sua utilização. Parturientes devem ser encorajadas a deambular ou adotar a posição que preferirem durante o primeiro período do parto. Imersão em água e suporte contínuo intraparto reduz efetivamente a dor no momento do parto. Hipnose e acupuntura são métodos não farmacológicos para alívio da dor que levam à redução significativa da necessidade de analgesia. A pesquisa ainda revelou que o uso do partograma em países de baixa renda se associa à redução das taxas de cesariana, assim como o manejo ativo do trabalho de parto com amniotomia e ocitocina não deve ser recomendado de rotina (8).

Todavia, todas as decisões sobre assistência ao primeiro período de parto devem ser discutidas previamente com as parturientes, sobretudo em situações em que não existem evidências suficientes para sua recomendação (9).

Destarte, uma recente revisão sistemática demonstrou que a cesariana planejada em comparação com o parto vaginal, reduziu a morte perinatal ou neonatal, bem como a morbidade neonatal grave, contudo revelou o aumento da morbidade materna (10) (11).

Outra pesquisa analisou a morbidade neonatal e materna e a mortalidade neonatal de acordo com o tipo de parto, cesariana ou vaginal. Foram estudadas prospectivamente 170 parturientes sem complicações gestacionais e com nascimento a termo: Grupo 1 ( $n=95)$, puérpera com parto por via vaginal, Grupo $2(n=75)$, puérpera submetida à cesariana. Foi observada maior incidência de partos por via vaginal nas pacientes que estudaram até o ensino fundamental incompleto. Observou a preferência de 78 (82,1\%) das mulheres do Grupo 1 pelo parto vaginal contra apenas 28 (37,3\%) das mulheres do Grupo 2, pela cesariana. Houve dor intensa no pós-operatório nas pacientes submetidas a parto cesáreo (oito casos). Traumas obstétricos foram verificados em catorze recém-nascidos do Grupo 1 e em sete do Grupo 2. Foi concluído que existe maior morbidade neonatal em recém-natos de parto por via vaginal quando comparada com neonatos de cesariana, bem como, maior morbidade materna em puérperas submetidas à cesariana (12). 
Um estudo comparou resultados com base nos dois anos após cesariana planejada e parto vaginal. Nos casos selecionados, as mães responderam a um questionário estruturado, retratando sua saúde nos últimos três a seis meses. Um total de 917 (79,1\%) em 1.159 mães de 85 centros, relataram que não houve diferenças entre os grupos em amamentação, relação com a criança ou parceiro, dor, gravidez subseqüente, incontinência urinária, depressão, problemas menstruais ou sexuais, fadiga ou memórias angustiantes com a experiência do nascimento. A única diferença significativa foi um aumento de constipação nas pacientes que realizaram cesariana. Em contrapartida, os recém-nascidos não foram protegidos da morte ou do dano cerebral por terem nascido de cesariana eletiva (13).

Dessa forma, as pesquisas buscam as melhores evidências disponíveis sobre indicações de cesariana, tais como placenta prévia, descolamento prematuro de placenta, placenta acreta, infecção por HIV, herpes genital, hepatites, HPV, condiloma genital, gestação múltipla, prolapso do cordão umbilical, distensão segmentar e ruptura uterina. Observou-se que a cesariana está formalmente indicada em algumas situações particulares, como na placenta prévia total. Em outros casos, pode haver indicação de cesariana intraparto, porém situações como HPV e gemelaridade não representam indicações para a realização do procedimento (3) (14).

Todas as mulheres em trabalho de parto devem ser avaliadas pelo médico, sendo que os eventuais riscos merecem ser expostos, uma vez que o manejo e o local do parto variam em função deste risco. A avaliação deve ser realizada inicialmente e durante todo o trabalho de parto. Pesquisas apontam que são várias as situações de riscos, dentre elas: (a) padrões anômalos de frequência cardíaca fetal; (b) falha de progressão; (d) sangramento; (e) apresentação pélvica; (f) parto disfuncional; (g) malformação cardíaca congênita; (h) outras malformações fetais reconhecidas; (i) restrição de crescimento intrauterino; (j) cardiopatia materna; (k) diabetes materno (clínico ou gestacional); (I) hipertensão materna; (m) lupus e outras colagenoses; (n) gestação múltipla; (o) oligohidrâmnio; (p) outras condições médicas crônicas ou agudas maternas e/ou fetais; (q) uso de ocitocina; ( $r$ gestação prolongada (maior ou igual que 42 semanas); (s) mecônio espesso (8).

A tomada de decisões baseadas nas melhores evidências é sempre a forma mais segura para o profissional da saúde e a paciente. Segundo alguns especialistas, a relação 
médico-paciente não deve ser vista como uma relação de consumo, sob a tutela do Código do Consumidor, uma vez que o resultado do trabalho do obstetra não pode ser equiparado à garantia de um bem de consumo ${ }^{15}$. Contudo, alguns estudos e até mesmo a jurisprudência dominante apontam que a relação médica é uma relação consumerista, pois, como fornecedor de serviços, independentemente da existência de culpa, há a responsabilidade pela reparação dos danos causados aos "consumidores" pelos defeitos relativos à má prestação de serviços (15) (17).

Independentemente de qualquer situação de risco ou não, a boa relação médicopaciente deve pautar-se pela transparência e confiança. Entre diferentes medidas recomendadas ao médico, há necessidade de permanente capacitação e atualização, o uso adequado de tecnologias e os tratamentos propostos que tenham indicações precisas (15) (16). Nessa linha, algumas pesquisas sugerem que os obstetras têm decidido suas intervenções sob a ótica do menor risco para si. Esta mudança de atitude tem sido justificada pelos inúmeros processos judiciais contra os profissionais de saúde, acarretando enorme custo emocional, psicológico e econômico para quem pratica obstetrícia (15) (17).

As denúncias relacionadas à prática médica obstétrica e ginecológica apresentadas no Conselho Federal de Medicina são frequentes, sendo quase $30 \%$ do total de queixas, segundo a Federação Brasileira das Associações de Ginecologia e Obstetrícia FEBRASGO (18), ainda porque, a obstetrícia é a especialidade de maior risco judicial dentro da prática médica, face ao grande número de intercorrências no período de prénatal e nas urgências e emergências no trabalho de parto (19).

Nesse contexto, o presente trabalho identificou no discurso dos julgadores do STJ a discussão dos conflitos que envolvem a seara da responsabilidade civil do médico obstetra frente às inúmeras intercorrências que ocorrem durante as tomadas de decisões, especialmente àquelas diretamente ligadas ao parto e puerpério.

As decisões apreciadas e julgadas pelo STJ nos anos de 2004 a 2014 foram selecionadas, com o objetivo de serem extraídos os principais posicionamentos dos Ministros da Corte, no tocante à responsabilidade objetiva do Hospital; a responsabilidade subjetiva do médico; a responsabilidade solidária do médico e hospital; as possíveis falhas na prestação de serviços, com base na relação de consumo; as provas produzidas e o 
convencimento dos Julgadores; as possíveis más práticas dos procedimentos (cesariana e parto natural), assim como o fato da técnica, dano, culpa e nexo causal.

\section{Métodos}

A pesquisa utilizou o método de análise do Discurso do Sujeito Coletivo (DSC) de Lefévre, com base, sobretudo nos pressupostos da "Teoria das Representações Sociais". A teoria elenca uma série de operações sobre a matéria-prima de depoimentos coletados em pesquisas empíricas de opinião, operações que redundam, ao final do processo, em depoimentos coletivos confeccionados com extratos de diferentes depoimentos individuais - cada um desses depoimentos coletivos veiculando uma determinada e distinta opinião ou posicionamento, redigidos na primeira pessoa do singular, com vistas a produzir, no receptor, o efeito de uma opinião coletiva, expressando-se, diretamente, como fato empírico, por meio do sujeito coletivo que "fala" (20). Esta técnica consiste em selecionar, cada discurso individual a uma questão, as expressões-chaves, que são trechos mais significativos destas respostas. As "expressões-chaves" correspondem as "ideias centrais" que são a síntese do conteúdo discursivo manifestado, que se constroem discursossíntese, na primeira pessoa do singular (21).

Optou-se pelo discurso dos Julgadores do Superior Tribunal de Justiça em razão desta Corte resolver, respectivamente, questões diretamente relacionadas com as normas federais em última instância, e uniformizarem o entendimento a respeito da matéria foco principal da pesquisa em caráter nacional, servindo de parâmetro para a resolução das demandas judiciais pelos juízes de primeira e segunda instância.

Ocorreram duas etapas de busca das decisões que abrangem 0 tema. Primeiramente, a seleção dos acórdãos foi realizada em um trabalho acadêmico (22), cujos resultados apontaram um universo de 90 (noventa) julgados extraídos do site do STJ num período de 2003 a 2013, que debatem sobre erros médicos, sendo 12 (doze) deles, referente às práticas danosas na obstetrícia. O levantamento dos julgados foi realizado no campo "pesquisa livre", utilizando os seguintes termos: "erro médico"; "médico"; "paciente"; "profissional da saúde"; "dano moral"; "dano material"; "SUS"; "responsabilidade civil" e "indenização por erro médico", escolheu-se a classe "Recurso Especial" que foram admitidos e julgados pelo STJ. 
Num segundo momento, foi realizada uma nova pesquisa, com o objetivo de abranger os casos julgados pelo STJ no período de 2004 a 2014. A busca foi realizada no campo "pesquisa livre" com os seguintes termos: "erro médico" e "parto". O resultado da pesquisa encontrou 13 (treze) decisões em "Recurso Especial" e em "Agravo Regimental no Agravo em Recurso Especial" que foram apreciadas pelo STJ, dos quais quatro deles constavam na primeira seleção das decisões, o que resultou num total de 21 (vinte e um) julgados.

Após a análise objetiva dos fatos e dados de cada caso, foram analisados os objetos de investigação, sendo possível identificar os fundamentos utilizados pelos julgadores, o entendimento externado acerca da matéria debatida, a fim de tornar possível a identificação de correntes de jurisprudência e a formação do perfil dos julgadores do STJ.

\section{Aspectos Éticos}

Ficou dispensada a aplicação do Termo de Consentimento Livre e Esclarecido, uma vez que o trabalho não envolve pesquisa com seres humanos, apenas descrição e análise do discurso dos julgadores do STJ, sendo os dados públicos, extraídos do site do Poder Judiciário.

\section{Resultados}

O trabalho revelou que a maioria das supostas falhas médicas obstétricas que originaram as ações indenizatórias, ocorreu durante a realização do parto normal, ou seja, $71 \%$, dos casos, comparado à cesariana com $29 \%$. As tabelas abaixo demonstram os danos e sequelas causados durante a realização de cada tipo de parto e o tipo de hospital, se público ou privado. Na Tabela 1, se observam os dados relacionados à cesariana.

A cesariana foi realizada em seis casos estudados, sendo dois deles decorrentes do esquecimento de material cirúrgico durante o procedimento. No primeiro caso, os autos retornaram à origem, uma vez que foi reaberta a oportunidade do hospital para comprovar a culpa exclusiva de terceiro (médico). No caso 4, a ação foi julgada procedente em virtude dos danos físicos, estéticos, morais e materiais (incapacidade funcional parcial) causados à parturiente. Neste caso indenizações somaram $R$ \$ 1.275.000,00. Ainda, em decorrência da prescrição irregular de medicação (caso2) e das complicações anestésicocirúrgicas, as sequelas causadas à mãe foram irreversívies: perda do útero e coma irreversível. 
No caso decorrente das complicações anestésico-cirúrgicas, restou evidenciada a negligência do hospital (caso 6) em não disponibilizar um profissional experiente e capacitado para acompanhar a médica residente, cursando o primeiro ano de residência, na realização de um procedimento complexo como a referida cirurgia. Concluiu-se pelo laudo pericial que a presença de um anestesista mais experiente talvez evitasse os problemas ocasionados à vítima, contando com todo aparato de monitoração e identificar a iminência de uma parada cardiáca, tomando as medidas necessárias para prevení-la.

A tabela 1 demonstra que a principal causa dos danos ligados ao parto normal, relatados nos acórdãos foi a demora na realização do parto, sendo apurado este fato em sete decisões, com os traumatismos em segundo lugar. As seqüelas irreversíveis ocorridas nos recém-nascidos predominam como os danos mais recorrentes, à frente dos óbitos fetais e dos danos irreversíveis sofridos pela mãe.

Sob o prisma da análise qualitativa das decisões, foram selecionados os debates centrais. As discussões abordadas nos discursos dos julgadores permeiam a seara da responsabilidade civil dos profissionais de saúde da área obstétrica, assim como as intercorrências ocorridas durante o pré-parto, o parto e pós-parto imediato, revelando como é a relação médico-mãe-feto, sob a ótica dos julgadores do STJ.

Os temas centrais extraídos dos discursos foram subdivididos em temas da fala de cada julgador, conforme as questões tratadas nas decisões, que foram objeto para construção do DSC, demonstrando o entendimento prevalente da jurisprudência acerca das expressões-chaves e as idéias centrais.

Foram selecionadas as seguintes questões, objetos de discurso pelos julgadores:

- A - Responsabilidade objetiva do Hospital;

- B - Responsabilidade subjetiva do médico;

- C - Responsabilidade solidária do médico e hospital;

- D - Falha na prestação de serviços - Relação de Consumo;

- E - Provas produzidas;

- F - Má prática dos procedimentos do parto cesáreo e natural;

- G - Fato da técnica;

- H - llegitimidade passiva da União. 
Dessa forma, a seguir apresentam-se as discussões predominantes, extraídas das expressões-chaves e as idéias centrais identificadas:

- DSC A - Discurso do Sujeito Coletivo acerca da responsabilidade objetiva do hospital

[...] Enquanto a responsabilidade do médico é subjetiva, a do hospital é objetiva. (art. 14 e $\S \S$ da lei 8078/90). Na prestação de serviço hospitalar, inverte-se o ônus da prova, visto que a hipótese encaixa-se perfeitamente nos ditames dos arts. $2^{\circ}$ e $3^{\circ}, \S 2^{\circ}$, do Código de Defesa do Consumidor, uma vez que o hospital caracteriza-se como autêntico prestador de serviços, quando deverá sua responsabilidade ser decidida sob o abrigo da responsabilidade civil objetiva, como dispõe o art. 14, do mesmo diploma legal, cabendo ao mesmo demonstrar que inexistiu defeito e que a culpa pela infecção hospitalar foi do paciente ou terceiro [...].

[...]A prestação de serviço hospitalar está tipificada nas disposições dos arts. $2^{\circ}$ e $3^{\circ}, \S 2^{\circ}$, do CDC, razão por que a sua responsabilidade é objetiva, nos termos do art. 14 do CDC [...].

[...] Cerceamento de defesa. Necessidade de prova pericial para que o hospital possa demonstrar que não houve responsabilidade da sua equipe auxiliar nem dos seus equipamentos, sendo ela, integralmente, da própria médica que realizou a cirurgia e esqueceu o corpo estranho no organismo da paciente. $O$ hospital recorre para provar que houve culpa exclusiva de terceiro, no caso a cirurgiã, o que é excludente de responsabilidade, nos termos do artigo $14, \S 3^{\circ}$, II do CDC [...].

\section{Comentários}

Para configuração da responsabilidade subjetiva do médico ou hospital, há necessidade da existência do dano, do nexo de causalidade e da culpa ou dolo. Isso significa que todos estes requisitos (dano, nexo causal, culpa/dolo) devem ser comprovados. Ressalta-se que a culpa se caracteriza pela conduta negligente, imprudente e imperita do agente causador do dano.

Para ser caracterizada a responsabilidade objetiva, ao contrário, independe de culpa do agente causador do dano. Isso porque, muito se discute se esta relação pode ser considerada como uma relação de consumo. O hospital é um fornecedor de serviços, equipamentos e medicamentos ao consumidor, mediante remuneração, nos termos do artigo 14 (23), caput do CDC, o que impõe ao prestador o dever de responder "independentemente de culpa", pelas reparações dos danos causados aos consumidores 
por defeitos relativos à prestação dos serviços, fornecimento de pessoal, material e equipamentos.

Ainda com base no disposto do artigo 37 (24), §6, da Constituição Federal, a responsabilidade do hospital é objetiva, independendo de atuar culposo ou doloso o respectivo preposto.

- DSC B - Discurso do Sujeito Coletivo acerca da responsabilidade subjetiva do médico

[...] A relação entre paciente e médico-hospital é de contrato de prestação de serviços entre as partes. Assim, a vítima e o autor do dano estão vinculados por uma relação jurídica preexistente. Quem se compromete a prestar assistência médica por meio de profissionais que indica, é responsável pelos serviços que estes prestam, respondendo, pois, de forma objetiva (art. 14, caput, CDC). Por outro lado, a responsabilidade pessoal do médico pela prestação de serviços deve ser apurada mediante culpa por força do art. 14, $\S 4^{\circ}$, do CDC [...].

[...] A conduta negligente do profissional que ocasionar lesão ao paciente acarreta-Ihe a obrigação de reparação dos danos. A instituição hospitalar, por sua vez, responde em decorrência do serviço prestado de forma irregular $[\ldots]$

[...] Na hipótese de prestação de serviços médicos, o ajuste contratual vínculo estabelecido entre médico e paciente - refere-se ao emprego da melhor técnica e diligência, entre as possibilidades de que dispõe o profissional no seu meio de atuação, em auxílio do paciente. Não se pode olvidar que, mesmo que os profissionais envolvidos empreguem toda sua diligência no ato, ainda assim podem advir reações imprevisíveis e situações inesperadas. Não podendo o médico assumir o compromisso com um resultado específico (exceto quando se tratar de cirurgia estética), outra não pode ser a teoria da responsabilidade que não a subjetiva, devendo-se averiguar se houve culpa do profissional [...].

\section{Comentários}

A conduta negligente do profissional que ocasionar lesão ao paciente acarreta-Ihe a obrigação de reparação dos danos. A instituição hospitalar, por sua vez, responde em decorrência do serviço prestado de forma irregular.

A responsabilidade do médico é tida como subjetiva, pois só responde quando ele der causa ao dano agindo com imprudência, negligência ou imperícia. Age o médico com imprudência quando pratica o ato sem o necessário cuidado. Com negligência quando se omite quando deveria agir. E imperícia quando o faz sem o necessário conhecimento que deveria ter. 
- DSC C - Discurso do Sujeito Coletivo acerca da responsabilidade solidária do médico e do hospital

[...] Restado comprovado que o médico, primeiro réu, foi negligente ao avaliar a mãe do autor, o que fez com que ele/autor nascesse com sequelas de natureza definitiva, deve ele (médico) ser condenado, solidariamente com o hospital, a pagar indenização, pelos danos morais causados [...].

[...] O sistema processual civil abraça o princípio do livre convencimento motivado, que, inclusive está positivado no artigo 131 do Código de Processo Civil, impondo ao julgador a indicação dos motivos de suas conclusões. Na hipótese em que a ação proposta tem sustentação na existência de erro médico, uma vez que realizada perícia, deve o julgador indicar os motivos pelos quais resolve concluir pela obrigação de indenizar, tomando posição oposta às conclusões do perito, mormente quando outras provas não existem nos autos. A responsabilidade do médico pressupõe o estabelecimento do nexo causal entre causa e efeito da alegada falta médica, tendo em vista que, embora se trate de responsabilidade contratual - cuja obrigação gerada é de meio - é subjetiva, devendo ser comprovada ainda a culpa do profissional [...]".

[...] Relativamente à responsabilidade dos hospitais, casas de saúde e similares, a melhor doutrina e a reiterada jurisprudência a têm como contratual, posto que ao admitir o paciente, seja em estabelecimento pago ou gratuito, estabelece-se entre as partes um contrato, e como tal, toma o hospital por obrigação o tratamento benévolo, tanto no que se refere à saúde quanto à hospedagem. Quando o hospital firma com o paciente internado um contrato hospitalar, assume as obrigações de meios consistentes em fornecer serviços médicos (quando o facultativo a ele pertence) ou apenas em fornecer hospedagem (alojamento, alimentação) e de prestar serviços paramédicos (medicamentos, instalações, instrumentos, pessoal de enfermagem, etc.). Tem-se que a autora foi atendida por seus prepostos, de forma negligente [...].

\section{Comentários}

Os profissionais de saúde e as instituições hospitalares, muitas vezes são condenados de forma solidária aos atos danosos eventualmente praticados. Em um dos casos, o hospital, apresentou contestação, denunciando à lide o médico. O Hospital foi condenado ao pagamento de indenização por danos morais no importe de 100 (cem) salários mínimos. Julgou, ainda, procedente a denunciação da lide para condenar solidariamente o médico (litisdenunciado) ao pagamento de indenização por danos morais no importe de 150 (cento e cinquenta) salários mínimos.

Foram unânimes os posicionamentos dos Julgadores do STJ quanto aos atos técnicos praticados de forma defeituosa pelos profissionais da saúde vinculados de alguma 
forma ao hospital, respondendo solidariamente a instituição hospitalar e o profissional responsável, apurada a sua culpa profissional.

Houve o entendimento de que a responsabilidade seria do médico que atuou diretamente no parto, mas também é do hospital ainda que não seja empregadora do médico obstetra, devendo responder, pois, no mínimo, o hospital deveria zelar pela qualificação e capacidade dos profissionais que atuam em suas dependências, bem como supervisionar os serviços prestados em seu estabelecimento, devendo ser lembrado que a paciente não procurou tão somente o profissional da saúde, e sim o nosocômio.

-DSC D - Discurso do Sujeito Coletivo acerca da falha da prestação de serviços relação de consumo

[...] A prestação de serviço hospitalar está tipificada nas disposições dos arts. $2^{\circ}$ e $3^{\circ}, \S 2^{\circ}$, do CDC, razão por que a sua responsabilidade é objetiva, nos termos do art. 14 do CDC, o que tem como consequência do ônus da prova. A relação existente entre as partes é de consumo. O réu, como fornecedor de serviços, responde, "independentemente" da existência de culpa, pela reparação dos danos causados aos consumidores por defeitos relativos à prestação de serviços, bem como informações insuficientes ou inadequadas sobre sua fruição e riscos', conforme estabelece o art. 14 do Código de Defesa do Consumidor[...].

\section{Comentários}

O entendimento prevalente é que a relação existente entre as partes é de consumo. O réu, como fornecedor de serviços, responde, "independentemente da existência de culpa, pela reparação dos danos causados aos consumidores por defeitos relativos à prestação de serviços, bem como informações insuficientes ou inadequadas sobre sua fruição e riscos", conforme estabelece o art. 14 (23) do Código de Defesa do Consumidor. Tal dispositivo adotou a teoria da responsabilidade objetiva, sendo certo que o estabelecimento hospitalar apenas ficaria isento da responsabilidade nas hipóteses previstas nos incisos I e II, do $\S$ 3ㅜ, do citado artigo 14.

Nos moldes do que preconizam os arts. 6으, VIII e 14, caput e $\S 3^{\circ}$, do CDC, cabe ao hospital-fornecedor demonstrar a segurança e a qualidade da prestação de seus serviços, devendo indenizar o paciente-consumidor que for lesado, em decorrência de falha naquela atividade. 
-DSC E - Discurso do Sujeito Coletivo acerca das provas produzidas

[...] O prontuário médico indica que não havia plantonista obstetra do hospital na sala de pré-parto, nem na de parto, e nenhum membro da equipe do nosocômio realizou exames na parturiente antes do procedimento cirúrgico, implicando omissão de socorro, eis que não interveio no nascimento da criança.[...]

[...]o perito foi categórico em afirmar que "a aplicação do fórceps de Simpson foi correta, mas em tempo de salvar a mãe e não o feto em sua inteireza. Quando aplicado o fórceps, certamente já estava o feto em sofrimento por prolongado período expulsivo sem descida pelo canal do parto além do plano III de Hodge (cabeça encaixada)". Desse modo, concluiu o expert do juízo que o uso do fórceps não contribuiu para o estado de saúde atual da menor, não ocorrendo erro técnico durante sua aplicação porque ausentes sinais de traumatismo fetal pela sua utilização, salientando que, na realidade os danos a menor foram ocasionados pela sua indicação tardia, tendo em conta que o que ocasionou a interrupção da oxigenação encefálica foi o hiato temporal (1 hora e 13 minutos) entre a parada de progressão em plano III de Hodge e a extração final do concepto[..].

[...] O próprio médico (f. 141-142) que acompanhou a gravidez da apelada e realizou o parto (natimorto) reconhece que "a auxiliar de enfermagem não pode fazer parto e nem pode examinar pacientes, para verificar se elas já estão ou não em trabalho de parto". A falta de condições daquele nosocômio aflora, ainda, do mesmo depoimento:... não existe médico de plantão na maternidade do hospital, razão pela qual o declarante e os outros médicos treinam as auxiliares em enfermagem para tirar os sinais vitais do feto e da gestante e detectar se estas já estão em trabalho de parto. Feita perícia, o médico perito não pôde atestar que a patologia apresentada pelo filho da autora era consequência da negligência do médico requerido. Aliás, a perícia foi clara quanto à ausência de negligência $[\ldots]$.

\section{Comentários}

A produção das provas documentais, testemunhais e periciais foi essencial para o convencimento dos julgadores, especialmente a prova técnica, a qual é realizada pelo perito médico do juízo.

Foi observado nos julgados que quando existente na prova pericial, a experimentação de danos pela pessoa e a presença do nexo de causalidade, resultou-se presente a obrigação de indenizar. Em todos os casos, a prova pericial foi elucidativa quanto ao nexo de causalidade entre a atuação dos médicos e as causas que ensejaram a responsabilização. 
- DSC F - Discurso do Sujeito Coletivo acerca da má prática dos procedimentos do parto natural e cesariana

[...] o feto não se encontrava em posição adequada, e mesmo assim, optaram por realizar o parto normal, quando seria necessária a realização de cesariana, causando danos irreversíveis à saúde da criança e ao estado psicológico dos genitores[..].

[...] demora na expulsão provavelmente por falta de material adequado, além da falta de monitorização adequada do feto para a detecção de sofrimento. Falta de material necessário e imprescindível à boa condução do parto[...]

[..] Durante a realização do parto, o feto entrou em sofrimento, abrindo a boca energeticamente e aspirando material verde-escuro produzido pelo seu intestino (denominado mecônio) e excretado no líquido amniótico pelo próprio feto. O líquido contaminado com mecônio provocou o colapso dos alvéolos pulmonares [...].

[..] o médico agiu, no mínimo, negligentemente, não só por não ter dispensado a assistência necessária à parturiente, mãe do autor, consciente da posição incomum do feto, como também por ter a deixado por horas prolongadas em observação aguardando a ocorrência do parto normal[...].

[...] Parturiente que é encaminhada a hospital de madrugada diante dos primeiros sinais do parto, é medicada com substância para induzir o nascimento da criança e depois deixada sozinha no leito, sem o adequado acompanhamento, vindo a ser socorrida apenas com a troca de plantonistas ocorrida de manhã, quando já verificado o óbito do feto[...].

[...] O erro médico consistiu na conduta negligente do médico em não optar pelo parto cesariana, na falta de acompanhamento da frequência cardíaca do feto, retirando-se o profissional da sala de parto no momento crítico da expulsão do recém-nascido[...].

\section{Comentários}

A má prática nos procedimentos médicos abrange elementos que podem ser extraídos da conduta culposa, ou seja, a conduta voluntária com resultado involuntário, a previsão ou previsibilidade e, por fim, a ausência de cuidado, cautela e diligência, sem a devida atenção às regras técnicas pertinentes ao seu exercício profissional.

- DSC G - Discurso do Sujeito Coletivo acerca do fato da técnica

[...] O laudo pericial concluiu que "é possível estabelecer nexo causal entre o parto realizado e a paralisia do membro superior direito apresentada pelo 


\begin{abstract}
filho periciando". Porém, em resposta aos quesitos formulados pelo próprio Apelante (quesitos 8 a 12 fls. 225/226), ficou suficientemente comprovado que não houve erro dos médicos. Ratificando esse entendimento, o laudo é taxativo ao concluir que os médicos atuaram com todas as precauções necessárias, incluindo a realização do procedimento que se mostrava mais adequado (parto obstétrico), e que era impossível prever, tampouco prevenir, o dano sobrevindo ao Apelante. Destarte, a conclusão da perícia comprova que a obrigação de meio da equipe médica foi cumprida e o resultado, ainda que não esperado, não revela desacerto profissional [...].
\end{abstract}

\title{
Comentários
}

O fato da técnica pode ser considerado excludente de responsabilidade civil quando analisada no caso concreto, sob a ótica da jurisprudência, uma vez que não há lei regulamentando sua aplicação. Isso porque apenas se baseia nos princípios constitucionais, como a ampla defesa, igualdade e principalmente a dignidade da pessoa humana.

Elias Kallas Filho (25), argumenta que o fato da técnica desqualifica o elemento culpa, ensejador da responsabilidade civil. Em alguns casos a excludente se assemelha à ausência de defeito por risco inerente, o que depende, portanto, da inevitabilidade do dano, mas não necessariamente de sua imprevisibilidade, isto é, excluirá a responsabilidade do médico quando verificada que a técnica utilizada, embora predominantemente benéfica e aprovada pela comunidade científica seja corretamente executada, mesmo sendo o dano existente.

A aplicação do fato da técnica reforça que, caso a obrigação de meio da equipe médica seja cumprida e o resultado, ainda que não seja o esperado, não poderá ser revelado "desacerto profissional".

- DSC H - llegitimidade passiva da União

[...] O acórdão recorrido está em contrariedade com a jurisprudência do STJ, firmada no sentido de que a União não possui legitimidade passiva nas ações de indenização por falha em atendimento médico ocorrida em hospital privado credenciado ao SUS, tendo em vista que, de acordo com a descentralização determinada pela Lei 8.080/1990, a responsabilidade pela fiscalização é da direção municipal do aludido sistema [...].

\section{Comentários}

No caso da demora no atendimento ao parto na rede pública nacional (SUS) foi concluído que a União, ré do caso, não tem legitimidade para figurar no polo passivo da 
ação. A ação foi julgada procedente na primeira e segunda instância, mas o STJ reformou a decisão, julgando extinta o feito sem julgamento do mérito. O posicionamento dos Ministros da Corte é unânime no sentido de ausência de responsabilidade da União acerca dos danos eventualmente causados pelos profissionais e centros de saúde relacionados ao Sistema Único de Saúde.

\section{Conclusão}

Pode-se dizer que as questões analisadas mediante os discursos dos julgadores do STJ, favorecem o estudo quali-quantitativo proposto, o qual mostrou-se um instrumento valioso para a geração de dados primários e secundários. Por meio da análise dos discursos, foram reveladas práticas obstétricas que ainda conflitam com os incentivos que os órgãos públicos e privados têm recorrido para reduzir o número de cesarianas. Isso ocorre, porque a vida está estritamente ligada à área obstétrica. Contudo, a bem da verdade ainda persiste nos sistemas e organizações de saúde a má gestão dos bens públicos, a falta de estrutura, a desorganização e os recursos escassos que só retardam a concretização das medidas adotadas na tentativa de humanização do parto.

É preciso reformular o modelo de assistência ao parto no Brasil e não apenas responsabilizar os médicos pelo excesso de cesarianas. Os discursos revelam discussões bastante relevantes, que podem ser repensadas como iniciativa para uma mudança gradativa nas relações entre os envolvidos no processo gestacional e puerperal, inclusive aos operadores do direito que de certa forma aplicam a lei (advogados, Poder Judiciário e demais instituições) ao caso concreto e os profissionais da saúde obstétrica (médicos, enfermeiros), que atuam diretamente com as dificuldades enfrentadas no exercício da profissão.

O trabalho revelou resultados que sugerem identificar o predomínio das correntes jurisprudenciais da Corte, a fim de obter subsídios para as organizações de saúde, sobretudo minimizar o ativismo judicial e os riscos decorrentes da má-prática médica obstétrica, reduzir custos provenientes das altas indenizações e incentivar a humanização, a qualidade e excelência na assistência ao parto. 


\section{Referências}

1. Brasil. Ministério da Saúde. DATASUS. Nascidos vivos no Brasil, 2013.. Disponivel em: http://tabnet.datasus.gov.br/cgi/deftohtm.exe?sinasc/cnv/nvuf.def. [Acesso em 25.abril.2014].

2. Brasil. Fiocruz - Nascer no Brasil. Pesquisa revela número excessivo de cesarianas; 2014. Disponível em http://portal.fiocruz.br/pt-br/content/pesquisa-revela-numeroexcessivo-de-cesarianas-no-pais. [Acesso em 25. set.2015].

3. Sass N, Hwang S. Dados epidemiológicos, evidências e reflexões sobre a indicação de cesariana no Brasil. Departamento de Obstetrícia, Universidade Federal de São Paulo Escola Paulista de Medicina (Unifesp-EPM), Diagn Tratamento. 2009;14(4):133-7.

4. Villar J, Valladres E, Wojdyla D, et al. Cesarean delivery rates and pregnancy outcomes: the 2005 WHO global survey on maternal and perinatal health in Latin America. Lancet. 2006;367(9525):1819-29.

5. Luis P, Paula A, Pereira E, Orlando A, Schilithz C. Sampling design for the Birth in Brazil : National Survey into Labor and Birth. Desenho da amostra Nascer no Brasil, 2014 1-10. Disponível em: http://www.scielo.br/pdf/csp/v30s1/0102-311X-csp-30-s1-0049.pdf. [Acesso em 10.fev.2015].

6. Eua O, Am N, Unido R. Editorial A questão das cesarianas. Rev Bras Ginecol Obstet. 2005;27(51):571-4.

7- Diniz CSG. Humanização da assistência ao parto no Brasil: os muitos sentidos de um movimento. Cien Saude Colet. 2005;10(3):627-37.

8. Porto AMF, Amorim MMR, Souza ASR. Assistência ao primeiro período do trabalho de parto baseada em evidências. Femina. 2010;38(10):527-37.

9. Clinical guidelines. Intrapartum care - care of healthy women and their babies during childbirth. London: National Collaborating Centre for Women's and Childrens's Health. Royal College of Obstetricians and Gynaecologists; 2007.

10. Hofmeyr GJ, Hannah M, Lawrie TA. Planned caesarean section for term breech delivery. Cochrane Database Syst Rev. 2015 Jul 21;7:CD000166. doi: 10.1002/14651858.CD000166.pub2. Review. PubMed PMID: 26196961.

11. Alfirevic Z, Milan SJ, Livio S. Caesarean section versus vaginal delivery for preterm birth in singletons. Cochrane Database Syst Rev. 2013 Sep 12;9:CD000078. doi: 10.1002/14651858.CD000078.pub3. Review. PubMed PMID: 24030708.

12. Cardoso PO, Alberti LR, Petroianu A. Morbidade neonatal e maternas relacionada ao tipo de parto. Cien Saude Colet. 2010;15(2):427-35 
13. Hannah ME, Whyte H, Hannah WJ, Hewson S, Amankwah K, Cheng M, Gafni A, Guselle P, Helewa M, Hodnett ED, Hutton E, Kung R, McKay D, Ross S, Saigal S, Willan A; Term Breech Trial Collaborative Group. Maternal outcomes at 2 years after planned cesarean section versus planned vaginal birth for breech presentation at term: the international randomized Term Breech Trial. Am J Clin Exp Obstet Gynecol. 2004 Sep;191(3):917-27. PubMed PMID: 15467565.

14. Sandro A, Souza R, Maria M, Amorim R, Maria A, Porto F. Indicações de cesariana baseadas em evidências: parte II. Femina. 2010;38(9):459-68.

15. Piazza MJ. Medicina defensiva e os ginecologistas e obstetras. Femina, 2012; 40

(1):1-4. Disponivel em: http://www.febrasgo.org.br/site/wp-

content/uploads/2013/05/Femina-v40n1_1-4.pdf. [Acesso em 14.out.2014].

16. La responsabilidad civil por defectuosa prestación de asistencia sanitaria al parto; 2012. Bliblioteca Unirioja. Disponível em: http://biblioteca.unirioja.es/tfe_e/TFE000236.pdf. [Acesso em 05.abril.2014].

17. Eroglu S., Toprak S., Urgan O, MD, Ozge E. Onur, MD, Arzu Denizbasi, MD, Haldun Akoglu, MD, Cigdem Ozpolat, MD, Ebru Akoglu M. Impacto de los dictámenes periciales del cendes en los procesos judiciales. Saudi Med J. 2012;33:3-8.

18. Federação Brasileira das Associações de Ginecologia e Obstetrícia - FEBRASGO. Erro Médico no dia a dia da ginecologia e obstetrícia; 2014. Disponível em: http://www.febrasgo.org.br/site/?p=2019. [Acesso em 05.mai.2014].

19. Nomura Seizo; Zugaib, Marcelo RMY; M. O perfil dos médicos denunciados que exercem ginecologia e obstetrícia no Estado de São Paulo. Rev Assoc Med Bras. 2006. 52:144-7. Disponível em: http://www.scielo.br/pdf/ramb/v52n3/a02v52n3.pdf. [Acesso em 15.nov.2014].

20. Lefevre F, Lefevre AMC. O sujeito coletivo que fala. Interface - Comun Saúde, Educ. 2006;10(20):517-24.

21. Lefevre AMC, Crestana MF, Cornetta VK. A utilização da metododologia do discurso do sujeito coletivo na avaliação qualitativa dos cursos de especialização "Capacitação e Desenvolvimento de Recursos Humanos em Saúde-CADRHU”, São Paulo - 2002. 200312(2):68-75. Disponivel em:: http://www.revistas.usp.br/sausoc/article/view/7099/8570. [Acesso em 08.abril.2015].

22 - Mota, Aline Veras Leite. Análise do Discurso da Jurisprudência do STJ nas indenizações por erro médico: impacto no sistema de saúde. [Dissertação de Mestrado]. Ribeirão Preto - Faculdade de Medicina de Ribeirão Preto - FMRP/USP, 2015.

23 - Brasil. Lei CDC - Lei no 8.078 de 11 de Setembro de 1990 dispõe sobre a proteção do consumidor e dá outras providências. Art. 14. O fornecedor de serviços responde, independentemente da existência de culpa, pela reparação dos danos causados aos 
consumidores por defeitos relativos à prestação dos serviços, bem como por informações insuficientes ou inadequadas sobre sua fruição e riscos. $\S 1^{\circ} \mathrm{O}$ serviço é defeituoso quando não fornece a segurança que o consumidor dele pode esperar, levando-se em consideração as circunstâncias relevantes, entre as quais: II - o resultado e os riscos que razoavelmente dele se esperam; III - a época em que foi fornecido. $\$ 3^{\circ} \mathrm{O}$ fornecedor de serviços só não será responsabilizado quando provar: I - que, tendo prestado o serviço, o defeito inexiste; II - a culpa exclusiva do consumidor ou de terceiro, 1990. Disponível em: http://www.planalto.gov.br/ccivil_03/leis/L8078.htm. [Acesso em 15.jan.2016].

24- Brasil. Constituição Federal do Brasil. Art. 37, § 6ำ As pessoas jurídicas de direito público e as de direito privado prestadoras de serviços públicos responderão pelos danos que seus agentes, nessa qualidade, causarem a terceiros, assegurado o direito de regresso contra o responsável nos casos de dolo ou culpa., 1988. Disponível em: http://www.planalto.gov.br/ccivil_03/Constituicao/Constituicao.htm. [Acesso em 17.jun.2014].

25 - Kallas Filho, Elias. O fato da técnica: excludente da responsabilidade civil do médico. R. Dir. sanit, Brasil, v. 14, n. 2, p. 137-151; 2013. ISSN 2316-9044. Disponível em: <http://www.revistas.usp.br/rdisan/article/view/63998>. [Acesso em 05.abril.2015]. 